\title{
Medicine and the making of interprofessional education
}

\section{INTRODUCTION}

Interprofessional education is a distillation of the investment made by the participating professions - medicine, nursing, allied health, social work and others - each instilling its values, knowledge, and skills accompanied by its preferred learning methods during a continuous process of negotiation and accommodation. This paper focuses on the contribution made in the UK by medicine. It distinguishes between two phases:

- the pioneering phase from 1966 to 1999 during which doctors led many of the early 'initiatives'; and

- the promotional phase since 2000 during which medicine seemed disconcerted but then reassured.

\section{THE PIONEERING PHASE}

Interprofessional education took root in the UK during the late 1960 s, driven by developments in primary and community care. Teamwork became the cornerstone for effective collaboration as primary care centres were established, but no panacea. Relationships between professions which may have worked well enough at arms length became fraught at close quarters. GPs were enthusiastic about the work of the district nurses, but critical of health visitors whose role some failed to understand. Others understood well enough, but felt that the advice given by the health visitors was at best unnecessary and at worst ill-conceived to the point of being harmful. ${ }^{1,2}$ These women stood accused of being interfering, even officious and impertinent towards patients, giving medical advice, often incorrect or in conflict with the GP's treatment, and undermining their authority with their patients. $^{3}$

As for social workers, GPs regarded them as relatively junior employees of the local authority, whose main functions were to find home helps, sort out financial problems, and rescue battered babies.
Neither GPs nor health visitors thought that social workers were trustworthy. They were hard to contact and slow to take action, did not offer a 24-hour service or remain long in the same post, never made time to discuss individual cases, and never provided feedback. ${ }^{1}$

Comments about GPs were scarcely less critical. According to the health visitors and social workers, they were difficult to contact, did not understand the work of other agencies, and withheld information of importance. Better cooperation between professions could not be achieved without major changes in both attitudes and working arrangements, but change was uncomfortable and threatening. ${ }^{2}$

Retired GPs who recall those days assure me that relations with their colleagues from other professions were invariably cordial and constructive, but there is evidence that doctors can be unaware of the stress which colleagues from other professions are experiencing. ${ }^{4-6}$

The same tensions were rehearsed during numerous workshops and conferences convened to help resolve the problems. The first was a 2-day symposium on 'Family Health Care: the Team' convened in London in 1966 by $\mathrm{Dr}$ Ekkehard Kuenssberg (1967) and sponsored, among others, by the Royal College of General Practitioners (RCGP). ${ }^{7,8}$

The RCGP with the health visitors and social work training bodies then recommended 'regional arrangements' for interdisciplinary meetings. The 'Windsor Group' discussed cooperation and conflict in community care and convened a 2-day seminar where GPs and social workers concluded that one of the most emotive issues was the extent and nature of future relations between their respective professions following the creation of social services departments in the wake of the 1969 Seebohm Report..$^{9,10}$ Freeing social workers from medical control had, according to delegates, led to problems, but improving working relations would need also to include health visitors, whose role was seen to overlap with those of both GPs and social workers. ${ }^{11}$

That debate prompted a 5-day seminar at Cumberland Lodge in Windsor Great Park where recently qualified practitioners from the three professions explored each other's roles and identities, dissipated prejudices, and acknowledged stresses in their working relations. GPs had reportedly failed to understand that health visitors had become independent practitioners with skills in preventive medicine, which in some ways went beyond their own. Neither GPs nor health visitors had yet accepted social workers' claims to their own specialist field. Many GPs preferred to pass social problems to health visitors when referrals to social services departments reportedly led to rejection, rationing, or delay. The core knowledge and skills of each profession, said delegates, had to command the respect of each of the others before liaison could be effective, and services become flexible and responsive. The roles of all three professions had broadened. Increasing overlap between them argued for common studies during pre-qualifying education.

A national conference held at the then Middlesex Polytechnic in 1984 was a landmark. It was organised by Michael Carmi (general practice), Valerie Packer (nursing) and Ann Loxley (social work) who had been running interprofessional short courses jointly for some time. Delegates backed a proposal to establish a permanent central organisation to support and coordinate interprofessional learning..$^{12}$ Further conferences followed, leading to the founding in 1987 of the Centre for the Advancement of Interprofessional Education in Primary Health and Community Care (as CAIPE was then known)..$^{13}$ John Horder, who had recently retired from general practice and completed his term of office as President of the RCGP, agreed, despite a recent 
health crisis, to take the lead and became CAIPE's first Chairman and later President.

Concurrently in Scotland, Ken Calman, then Professor of Clinical Oncology at the Glasgow Medical School, was the driving force behind 'Interact', a rolling programme of conferences for interprofessional activists moving from city to city. The interprofessional movement owes much to his support throughout his long and distinguished career in medicine and academe, notably his proposals as Chief Medical Officer for England for 'practice professional development plans' in primary care which put teamwork and interprofessional education at their heart. ${ }^{14}$

Back in London, Patrick and Marilyn Pietroni were pioneering interprofessional education with the Marylebone Centre Trust. Jungian analyst and Freudian psychotherapist respectively, they introduced psychodynamic insights to cultivate a holistic understanding of interprofessional education and practice within which the complementary therapies were assured of a place..$^{15}$

Applying Jung's theory of archetypes, Patrick saw the doctor as 'the hero-warrior god', the nurse as 'the great mother', and the social worker as 'the scapegoat', a role inherited from the medieval witch via the midwife who had successfully escaped such stigma. A fourth archetype was 'the trickster', like Hermes and Mercury bearing Caduceus' staff as they carried messages between God and man. Slippery and cunning, the trickster for Patrick resembled not medicine but psychotherapy. If some of us struggled to distinguish between archetypes and stereotypes, which interprofessional learning existed to challenge, we joined in the fun when participants at one workshop were invited to caricature themselves and others. The social work students saw themselves as Guardian readers into health foods; medical students as beer drinking rugby players; and nursing students as caring but unimaginative. The medical students saw social work students as left wing, selfopinionated but intellectual, driving deux chevaux; nursing students as having chips on their shoulders; and themselves as naïve and (agreeing with the others) arrogant. $^{16}$
The Trust launched the Journal of Interprofessional Care in 1992, with Patrick as its first editor, and destined to become the dedicated channel for national and later international exchange of scholarship in interprofessional education, practice, and research. It was also instrumental in bringing interprofessional education into universities, mounting the first interprofessional masters' programme, validated by the University of Westminster.

The seeds of university-based interprofessional education were also being sown at Exeter where Denis Pereira Gray, then Head of the Postgraduate Medical Education, with Rita Goble from occupational therapy, instigated postgraduate and masters programmes to secure firmer academic and research foundations for non-graduate entrants to nursing, social work, and the allied health professions, with an interprofessional twist. ${ }^{17}$

Shared learning between health and social care professions during preregistration studies was developing in parallel, but minus medicine and interprofessional learning. ${ }^{18}$ It was the 1980s before the first examples were reported, in Bristol, where medical students shared modules with nursing and social work students. ${ }^{19,20}$

Numerous initiatives were bringing together newly qualified practitioners, for example, one by John Hasler in Oxford ${ }^{21}$ and by Oliver Samuel in London, ${ }^{22}$ while Bob Jones was running 'novice days' in Exeter. ${ }^{23}$ GPs were also writing teamwork texts. ${ }^{23-28}$

By the 1980s interprofessional education was no longer preoccupied with introspection about problematic relationships; it was more positive, more outward looking, more intent on exploring how the professions together could be more effective in improving services and promoting healthier lifestyles. Problematic relationships could be dealt with if and when necessary.

Paul Thomas ${ }^{29}$ in Liverpool led a 5-year primary healthcare development programme during which facilitators worked with their fellow GPs and nurses to break down isolation between practices, to promote the employment of practice nurses, and to encourage a reorientation from one-off treatment of disease to participation in health. Among a plethora of activities, mentors were designated to support the rapidly growing number of practice nurses, but the initiative which I relished especially was the one where interviewers discussing healthy lifestyles with patients in the waiting room dispensed daffodils in exchange for cigarettes!

Nationwide, Deryck Lambert ${ }^{30}$ was injecting much the same energy into health promotion in primary care during a travelling circus of workshops mounted by the Health Education Authority. 'Triads' were invited from the same primary health care team, each of which selected a health promotion priority to translate into a training strategy during the workshop and implement 'back at the ranch', reporting progress during a recall day.

\section{THE PROMOTIONAL PHASE}

The turn of the century was a watershed. Interprofessional education was no longer marginal; it was entering the mainstream of professional education. No longer confined to post-experience studies; it was being embedded in pre-registration programmes. No longer dealing in penny numbers; it was catering for student intakes counted in thousands. No longer bottom-up; it was top-down. No longer practice-driven; it was responding to a raft of modernisation policies. ${ }^{31-34}$ No longer passing fashion; it was here to stay. Doctors were by no means alone in fearing that interprofessional education was being driven too far too fast, without waiting for pilot projects to report ${ }^{35,36}$ or evidence to be assembled. ${ }^{37,38}$

The challenges were many. Stakeholders thrashed out their differences and pressed competing claims for inclusion in crowded curricula; claims ranging from health promotion to service improvement, to patient safety, to multitasking, each with different implications for interprofessional curricula. Successful joint planning depended on resolving status differentials. Courses for nursing, social work, and the allied health professions were often in the new universities; for medicine, dentistry, and pharmacy in the old. Differences in history, ethos, and culture militated against 
partnership. While much of the drive behind interprofessional education was generated within the new universities accustomed to working with local employers and responding to government policy, the old universities were more precious and more protective. Albeit difficult, partnerships were established between new and old.

Presentation was another problem. 'Common learning' had become the catchphrase commended by government and adopted by employing agencies to convey togetherness and solidarity, but unhelpful when construed from a professional perspective as dumbing down, denying difference, or detracting from 'uncommon' learning. The case for a foundation of common learning was incontrovertible to establish shared values and understanding of policy and organisational context, but unhelpful when it failed to build in differential application to practice.

The lead that general practice had once given was slipping away as the new universities with which they were unfamiliar and a new generation of teachers from health sciences took over, while teaching teamwork, by which GPs rightly set much store, seemed less in vogue. ${ }^{37,39}$

All of which makes unequivocal backing today for interprofessional education by leading medical institutions the more remarkable. One explanation may be the lead given by the medical education associations:

- SCOPME - the Standing Committee on Postgraduate Medical and Dental Education;

- AMEE - the Association for Medical Education in Europe;

- ASME - the Association for Medical Education; and

- MEDVED - the Medical, Dentistry and Veterinary Subject Centre of the Higher Education Academy.

SCOPME ${ }^{40}$ was in favour, but concluded that there was no one right way to achieve effective 'multiprofessional learning and working'. AMEE was more up-front as Ron Harden took us on his magical mystery tour in search of interprofessional education. ${ }^{41}$ ASME also supported interprofessional education led by Frank Smith. More recently, MEDVED implanted interprofessional teaching and learning in medical education, in partnership with other Higher Education Academy subject centres.

A second explanation may be the impact of the RCGP. Name after name on its 'roll of honour' has backed the interprofessional cause reinforced by papers in its Journal and off-prints, by the Prince of Wales Fellowship Scheme, ${ }^{42}$ and, most recently, plans for the GP Foundation to advance education and professional standing for practice managers, nurses, and physician assistants.

A third explanation may be messages reaching regulatory and professional bodies from medical students and teachers, confirmed by Sir Liam Donaldson (the Chief Medical Officer) ${ }^{34}$ who asserted that some medical schools had successfully introduced learning across professions and reinforced by Sir Graeme Catto as President of the GMC from his firsthand experience of piloting interprofessional education at King's College London.

It is, however, doubtful whether we should have witnessed such dramatic endorsement of the interprofessional cause by medicine had it not been for the Kennedy Inquiry into the untoward death of children undergoing cardiac surgery at the Bristol Royal Infirmary. In Sir lan Kennedy's own words:

'The story - is not an account of bad people. Nor is it an account of people who did not care - [but] ... many failed to communicate with each other, and to work effectively together for the good of the patients. There was a lack of leadership and teamwork. ... [In] a hospital where there was a club culture which hindered a multiprofessional approach to reviewing care. ${ }^{43}$

Kennedy was shocking, challenging, but strangely reassuring: shocking in his indictment; challenging in prompting reappraisal of questionable assumptions by interprofessional exponents which prioritised collaboration in communitybased care; and reassuring in reaffirming the centrality of patient safety and quality of care in interprofessional learning and working to which all parties could subscribe unreservedly.

The Royal College of Physicians (RCP), the British Medical Association (BMA) and the General Medical Council (GMC) have all now thrown their weight behind interprofessional education to realise their longstanding ambitions for interprofessional teamwork. From the RCP:

'Multidisciplinary healthcare teams are the indivisible units for delivery of quality health services. But overall doctors have not spent sufficient time learning from other members of the health care team ... we recommend that the GMC ... and medical schools explore ways of strengthening common learning to enable better interprofessional education and training. ${ }^{344}$

From the BMA:

'Emerging evidence suggests that interprofessional education can, in favourable circumstances and in different ways, contribute to improving collaborative practice, although further research is needed. Effective teamworking, collaboration and communication across professional boundaries are vital and interprofessional education a means to those ends. Such education focused not only on the subject matter, but also on the way in which practitioners worked together, taking in account appreciation of different ways of working, and the strengths of a diverse workforce. ${ }^{45}$

From the GMC, ${ }^{46}$ 'tomorrow's doctor' will:

- understand and respect the roles and experience of health and social care professionals in the context of working and learning as a multiprofessional team;

- understand the contribution that effective interprofessional teamwork makes to the delivery of safe and quality care; and

- work with colleagues in every way that best secures the interest of patients. 
Medical schools must, asserts the GMC, ensure that their students work and learn from other health and social care professionals and students. Implementing that requirement cries out for monitoring, especially how visiting panels to medical schools appraise progress and feedback to them and to the GMC.

\section{Hugh Barr}

\section{REFERENCES}

1. Jeffereys M. The anatomy of social welfare services. London: Michael Joseph, 1965.

2. Bruce N. Teamwork for preventive care. Chichester: Research Studies Press, 1980.

3. Dingwall R. Problems of teamwork in primary care. Wolfson College Oxford: Centre for Socio-Legal Studies, 1978.

4. Baggs J, Schmitt M, Mitchell P, et al. Association between nurse-physician collaboration and patient outcomes in three intensive care units. Crit Care Med 1999; 27(9): 1991-1998.

5. Reeves S, Nelson S, Zwarenstein M. The doctor-nurse game in the age of interprofessional care. Nurs Inq 2008; 15(1): 1-2.

6. Rosenstein A. Orinigal research: nurse-physician relationships: impact on nurse satisfaction and retention. Am J Nurs 2002; 102(6): 26-34.

7. Horder J. Dr Ekke Kuenssberg (a tribute). CAIPE Bulletin 1974, 7 Summer.

8. Kuenssberg E. Conference report, family health care: the team. London: Royal College of General Practitioners, 1997.

9. Bennett P, Dewar A and Dick A. Inter-professional cooperation. J R Coll Gen Pract 1972; 22: 603.

10. Seebohm. Report of the committee on local authority and allied personal social services. London: HMSO, Cmnd. 3703, 1969.

11. Martin R, Mond N. General practitioners and the social services departments. J R Coll Gen Pract 1971; 12: 101-104.

12. Carmi M. The emergence of CAIPE. In: Members' reference book. London: Royal College of General Practitioners, 1991.

13. Horder J. A history of the Centre for the Advancement of Interprofessional Education. Unpublished, 2003.

14. Department of Health. A review of continuing professional development in general practice: a report of the Chief Medical Officer. London: Department of Health, 1998.

15. Pietroni J, Pietroni P. Innovations in community care and primary care. Edinburgh: Churchill Livingstone, 1996.

16. Pietroni PC. Stereotypes or archetypes? A study of perceptions amongst health care students. Journal of Social Work Practice 1991; 5(1): 61-69.

17. Pereira Gray D, Goble R, Openshaw S, et al. Multiprofessional education at the Postgraduate Medical School, University of Exeter, United Kingdom. Annals of Community Oriented Education 1993, 6: 181-190.

18. Mortimer E. Interdisciplinary learning at the qualifying and post-qualifying stages. In: $\mathrm{H}$ England, (ed). Education for co-operation in health and social work: papers from a symposium in interprofessional learning, University of Nottingham, July 1979. London: Royal College of General Practice, 1980

19. Carpenter J. Interprofessional education for medical and nursing students: evaluation of a programme. Med Educ 1995; 29(4): 265-272.
20. Carpenter J, Hewstone M. Shared learning for doctors and social workers. Br J Soc Work 1996; 26(2): 239-257.

21. Hasler J, Klinger M. Common ground in general practitioner and health visitor training: an experimental course. J R Coll Gen Pract 1976; 26(165): 266-274.

22. Samuel O, Dodge D. A course in collaboration for social workers and general practitioners. J R Coll Gen Pract 1981; 31(224): 172-175.

23. Jones R. Working together - learning together. Occasional Paper 33. London: Royal College of General Practitioners, 1986

24. Hasler J. The primary care team. London: Royal Society of Medicine, 1994.

25. Butrym Z, Horder J. Health, doctors, and social workers. London: Routledge \& Kegan Paul, 1983.

26. Pritchard P, Pritchard J. Teamwork for primary and shared care: a practical workbook. 2nd edn. Oxford: Oxford University Press, 1994.

27. Pringle M. Change and teamwork in primary care. London: BMJ Publishing Group, 1993.

28. Elwyn $\mathrm{G}$ and Smail J. Integrated teams in primary care. Oxford: Radcliffe Medical Press, 1999.

29. Thomas P. The Liverpool Primary Health Care Facilitation Project 1984-1994. Liverpool: FHSA, 1994

30. Lambert D. Team workshops for health promotion in primary health care organized by the Health Education Authority. London: Health Education Authority, 1988.

31. Department of Health. The NHS Plan. London: Department of Health, 2000.

32. Department of Health. A health service for all the talents: developing the NHS workforce. London: Department of Health, 2000.

33. Department of Health. Working together, learning together: a framework for lifelong learning for the NHS. London: Department of Health, 2001.

34. Department of Health. Medical schools: delivering the doctors of the future: a report by the Chief Medical Officer. London: Department of Health, 2004.

35. Barr H. Piloting interprofessional education: four English case studies. (Other) London: Higher Education Academy, Health Sciences and Practice Network, 2007, Occasional Paper No.8.

http://www.health.heacademy.ac.uk/publications/occas ionalpaper/occp8.pdf (accessed 12 Mar 2010).

36. Miller C, Wolf C, Mackintosh N. Evaluation of common learning pilot and allied health first wave sites. London: Department of Health, 2006.

37. Barr H, Koppel I, Reeves S, et al. Effective interprofessional education: argument, assumption \& evidence. Oxford: Blackwell, 2005.

38. Hammick M, Freeth D, Koppel, et al. A best evidence systematic review of interprofessional education. Dundee: BEME Guide 9. Med Teach 2007; 29(8): 735-751.

39. Miller C, Freeman M and Ross N. Interprofessional practice in health and social care: challenging the shared learning agenda. London: Arnold, 2002.

40. SCOPME. Multiprofessional learning and working: sharing the educational challenge. London: Standing Conference on Postgraduate Medical Education, 1997

41. Harden R. AMEE guide No. 12: Multiprofessional education: Part 1 - effective multiprofessional education: a three-dimensional perspective. Med Teach 1998; 20(5): 402-408.

42. Billingham K, Flynn M and Weinstein J. Making a world of a difference: developing primary health care. London: Royal College of General Practitioners, 1999.

43. Kennedy I. Bristol Royal Infirmary Inquiry: final report. London: HMSO, 2001.

44. Royal College of Physicians. Doctors in society: medical professionalism in a changing world. Report of a Working Party of the Royal College of Physicians of London. London: RCP, 2005.
45. British Medical Association. Interprofessional education: a report by the Board of Medical Education. London: BMA, 2006.

48. GMC. Tomorrow's doctors. London: General Medical Council, 2009.

DOI: 10.3399/bjgp10X484039 